\title{
Sintering Kinetics of the Powder during Fields-Activated Micro-forming and Sintering (Micro-FAST) of Copper Micro-Gears
}

\author{
Kunlan Huang ${ }^{1 \& 2, a}$, Yi Yang ${ }^{1, b}$ and Yi Qin ${ }^{2, c}$ \\ ${ }^{1}$ School of Manufacturing Science and Engineering, Sichuan University, Chengdu, Sichuan, 610065, \\ P.R. China \\ ${ }^{2}$ Center for Micro-Manufacturing, Dept. of DMEM, University of Strathclyde, James Weir Building. 75 \\ Montrose Street, Glasgow G1 1XJ, UK \\ akunlan.huang@strath.ac.uk, ${ }^{\mathrm{b}}$ yangyi@scu.edu.cn, ${ }^{\mathrm{c}}$ qin.yi@strath.ac.uk
}

Keywords: Sintering kinetics, Field-activated sintering technology (FAST), Micro-forming

\begin{abstract}
Forming of micro-components from powder with fields-activated sintering technology (FAST) renders different forming and sintering mechanisms, comparing to that occurring during the forming of macro-sized components with a similar technology. Establishing a good understanding of these mechanisms would help process design and control aiming at achieving desired quality of the components to be formed. This paper presents a study and the results on the sintering kinetics of the powder during Micro-FAST for the fabrication of micro-gears (the module is 0.2 and the pitch diameter $1.6 \mathrm{~mm}$ ) from copper powder. The results showed that the densification of copper powder is related largely to the bulk plastic-deformations of the particles and the melting of the particles at contact interfaces. Particularly, it is revealed that plastic deformations of the copper particles mainly occurred at approximately $340{ }^{\circ} \mathrm{C}$ and melting of the particle-interfaces at approximately $640{ }^{\circ} \mathrm{C}$. Differently, in a densification process with a traditional powder sintering method, grain growth and neck growth would, normally, be two dominant mechanisms that achieve the densification of powder.
\end{abstract}

\section{Introduction}

In recent decades, the development towards miniaturization of products and devices in industries such as electronics, optics, communications, etc. has increased the demand for metallic parts manufactured at micro-scale. Such parts encompass a wide variety of geometries, materials, functionalities and production processes. Examples of micro-parts include screws, fasteners, connector pins, springs and micro-gears. During the last 10 years, various micro metal-forming processes have been studied and used to produce a variety of micro-metal-components [1] and these efforts were highlighted particularly by the EU large-scale integrated project MASMICRO which researched and produced various manufacturing facilities for micro-manufacturing [2] as well as recently funded EU Micro-FAST project for the development of an integrated system for volume production of micro-components by combining micro-forming and electric-field activated sintering (http://www.micro-fast.eu/).

External electric field-activated sintering technology (FAST) has been widely investigated and applied for the forming of macro-sized components [3, 4]. These methods were however, rarely utilized for the manufacture of miniature and micro-sized components, largely due to lack of understanding of the mechanisms of powder sintering at the micro-scale. A novel micro-forming technology, named Micro-FAST (combining micro-forming and FAST), was proposed recently by the present authors for the forming of micro-components. Gears made of $316 \mathrm{~L}$ stainless and $\mathrm{Cu}$ powder at the micro-scale have been fabricated successfully $[5,6]$. As the process illustrated in Fig.1, Micro-FAST is a method which can be used for the forming of micro-components with a variety of material systems, for instance, metals, ceramics and composites. Compared with conventional micro-forming methods, this manufacturing method presents more merits: lower sintering temperature, shorter forming time and remarkable improvements in sintering density. In 
Micro-FAST, the powder is formed/sintered under simultaneous actions from the coupled multi-physical fields (electric field, temperature field and pressure field). Moreover, loose powder is loaded directly into the die, and the heating is achieved through passing an $\mathrm{AC}$ current through the die to generate the necessary temperature in the powders, and pressure is applied onto the powders simultaneously. The direct manufacture from powder with no binders added to the powder indicates that it is an energy conserving and environmentally friendly forming process. Another significant aspect is that the nano-structures of the materials in the formed parts can be maintained, due to the ultra-fast processing time, and hence, excellent mechanical properties.

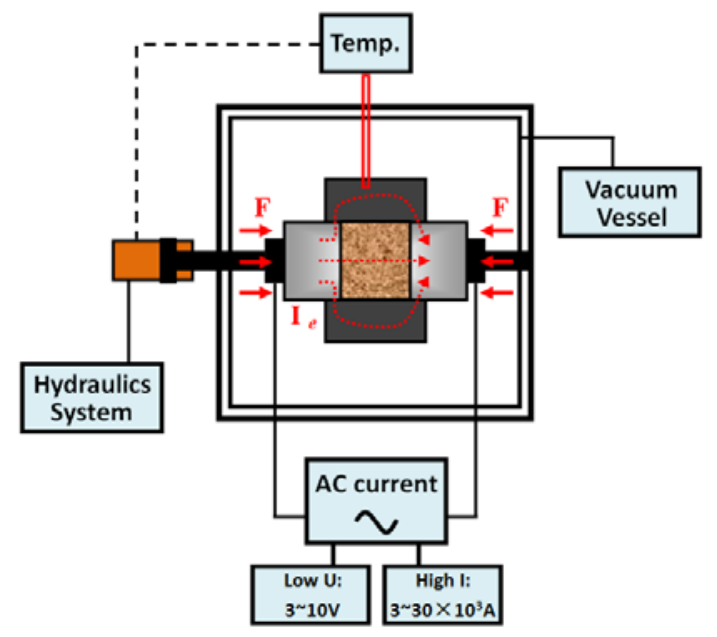

Fig.1 Illustration of the Micro-FAST sintering and forming process

V.V. Dabhade et al [7] reported that the mechanism for powder metallurgy could be volume diffusion or grain boundary diffusion or the simultaneous occurrence of both. For the densification process in a traditional powder sintering method, grain growth and neck growth are the critical mechanisms that achieve densification. Grain growth is caused by coarsening which is associated with either surface diffusion or evaporation/condensation, and generally not associated with densification [8]. Hanna Borodianska et al. [9] have also studied densification by a grain-boundary diffusion mechanism as for conventional sintering and the contribution from the specific pressure-assisted mechanisms for hot pressing is insignificant. Actually, the diffusion rate is determined by temperature, powder characteristics and sintering time. J.-S. Lee et al. [10] established that volume diffusion would take a long time, about a few hours. However, with continuous high-pressures being applied and ultra-fast forming time, Micro-FAST occurs without the coarsening of grains during the densification process. Joule heating is the main heat source during the sintering process and thus it has different densification mechanisms compared to those of conventional processes (including FAST). For example, the mechanical plastic deformation and interface melting of particles make a great contribution to the densification of powders during the Micro-FAST [5].

The goal of this work was to study the sintering kinetics of Micro-FAST in the fabrication of the copper gears. This kind of work has not been done by other researchers. According to the sintering temperature and axial reduction curves, which were collected by a Gleeble-1500D thermal simulation machine, an attempt was made to find the temperature point of plastic deformation and interface melting of particles, and then help to improve the process understanding and component quality.

\section{Experimental procedure}

Pure copper powder (99.9\% purity) with an average particle size of $20 \mu \mathrm{m}$ was used for the experiments. The starting powders were loosely agglomerated. Moreover, the atomized powder exhibited a near-perfect spherical shape and a homogeneous size distribution. Fig.2 is a schematic illustration of the tool-set used in the experiments with a Gleeble-1500D thermal simulation machine 
from Dynamic System Inc., USA. The electric field produced by the machine has low voltage and high current (3 10 V and 3,000 30,000 A). The as-received powder consisted of agglomerates which were sufficient for making up a micro-gear with a pitch diameter of $1.6 \mathrm{~mm}$. After weighing, the powder was loaded into a die, a model of which is shown in Fig.2. Next, the die filled with copper powder was placed into the Gleeble-1500D machine, and then heated rapidly to a particular sintering temperature at a preset heating rate in a vacuum $\left(<10^{-4} \mathrm{~Pa}\right)$ (a high electric current passes through the die set), and at the same time, a preset pressure was applied to the punch. The detailed technological parameters of the experiments are given in Table1.

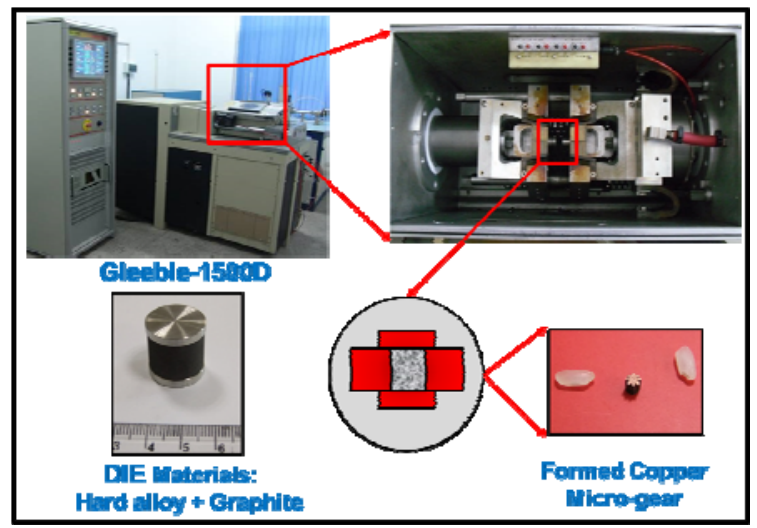

Fig.2 Tool-set used and experimental set-up with a Gleeble-1500D

Table1. The processing parameters corresponding to the samples formed

\begin{tabular}{|c|c|c|c|c|c|c|}
\hline $\begin{array}{c}\text { Specimen } \\
\text { designation }\end{array}$ & $\begin{array}{c}\text { Heating } \\
\text { rate }\left({ }^{\circ} \mathrm{C} / \mathrm{s}\right)\end{array}$ & $\begin{array}{l}\text { Pressure } \\
\text { on the } \\
\text { punch } \\
(\mathrm{MPa})\end{array}$ & $\begin{array}{c}\text { Sintering } \\
\text { temperature } \\
\left({ }^{\circ} \mathrm{C}\right)\end{array}$ & $\begin{array}{l}\text { Number of the } \\
\text { heating cycle* } \\
\left(\mathrm{T} \sim 400^{\circ} \mathrm{C}\right)\end{array}$ & $\begin{array}{l}\text { Total } \\
\text { using time } \\
\text { (s) }\end{array}$ & $\begin{array}{c}\begin{array}{r}\text { Relative } \\
\text { density }\end{array} \\
(\%)\end{array}$ \\
\hline $1 \#$ & 50 & 75 & 200 & 0 & 48 & 73.46 \\
\hline 2\# & 50 & 75 & 300 & 0 & 55 & 79.87 \\
\hline $3 \#$ & 50 & 75 & 400 & 0 & 62 & 86.04 \\
\hline $4 \#$ & 50 & 75 & 500 & 0 & 69 & 89.15 \\
\hline 5\# & 50 & 75 & 600 & 0 & 76 & 91.27 \\
\hline $6 \#$ & 50 & 75 & 700 & 0 & 83 & 96.63 \\
\hline 7\# & 50 & 75 & 700 & 3 & 100 & 99.01 \\
\hline
\end{tabular}

* A heating cycle is defined as a cycle during which the temperature rises to the maximum value and then drops to about $400{ }^{\circ} \mathrm{C}$

The sintered compact's density was measured using an electronic analytical balance, TP-214. The microstructure of the fracture surface was observed under a scanning electron microscope, JSM-5900LV, JEOL (Japan). The axial reduction and sintering temperature curves of the copper micro-gears were measured using a Gleeble-1500D thermal simulation machine from Dynamic System Inc., USA.

\section{Results and discussion}

The morphology of a formed sample can be seen in Fig.2, which latter displays a well-shaped profile. This micro-gear, with 8 teeth, was fabricated to a module of 0.2 and a pitch diameter of $1.6 \mathrm{~mm}$. The calculated relative densities of the sintered samples are given in Table 1. As shown in this table, the relative density of the samples depends greatly on the sintering temperature and a tendency towards an increase in relative density was observed. It can be noted that the $7 \#$ micro-formed sample has a large relative density of $99.01 \%$. 


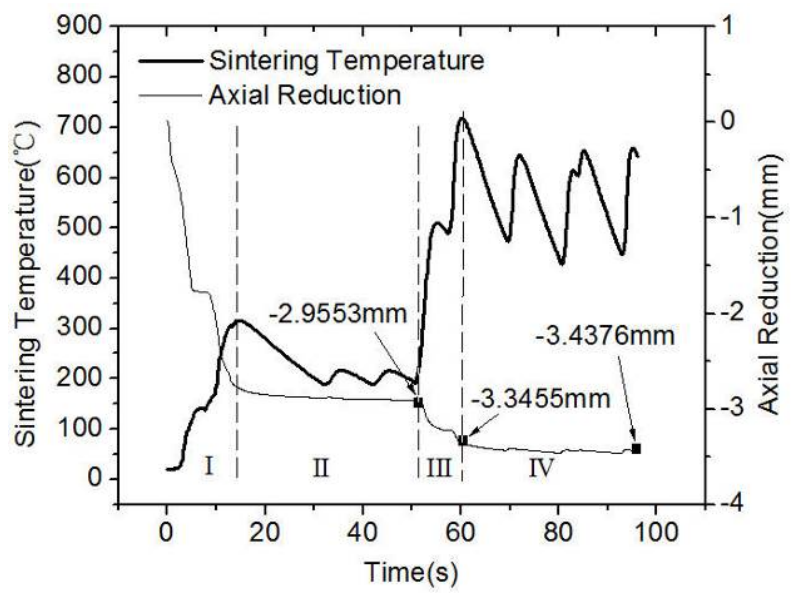

Fig.3 The sintering temperature and axial reduction of the 7\# micro-gear as a function of time

Fig. 3 shows the temperature and axial reduction profiles of the sample $7 \#$ during the heating process. According to the characteristics of this temperature profile, the process can be described in four stages:

(i). Preheating period (from room temperature to the beginning of holding at $200{ }^{\circ} \mathrm{C}$ ). The onset temperature at the point where the axial reduction increases indicates that the loose powders are being rearranged and compressed tightly due to the pressure applied to the die and the punch.

(ii).Warm-holding period (keeping at $200^{\circ} \mathrm{C}$ for about 30 seconds). This step is to eliminate the effect of residual gas entrapped within the die system. The actual temperature of these compacts during the experiments was measured and recorded using a thermocouple. The results show that a large fluctuation of temperature occurs at the holding step, while a flat axial reduction curve is obtained and indicate that the changes in the particles, such as deformation or interface melting, wouldn't occur at a low temperature of $200^{\circ} \mathrm{C}$ and pressure of $100 \mathrm{MPa}$.

(iii). Temperature-rise period (from the end of holding at $200{ }^{\circ} \mathrm{C}$ to the preset temperature at 700 ${ }^{\circ} \mathrm{C}$ ). This period is defined as the main densification realized process where the axial reduction increases rapidly (from $-2.9553 \mathrm{~mm}$ to $-3.3455 \mathrm{~mm}$ ) with the temperature rising, which is shown in Fig.3. It is worth mentioning that there was a very obvious axial shrinkage of sample that occurred, which is a result of deformation and interface melting of particles and has been noted by authors $[5,6,11]$.

(iv). Heating cycle period. According to the axial reduction trend and reduction value from -3.3455 $\mathrm{mm}$ to $-3.4376 \mathrm{~mm}$, it can be concluded that the heating cycle made a slight contribution to the densification of the samples.

\section{Sintering kinetics analysis}
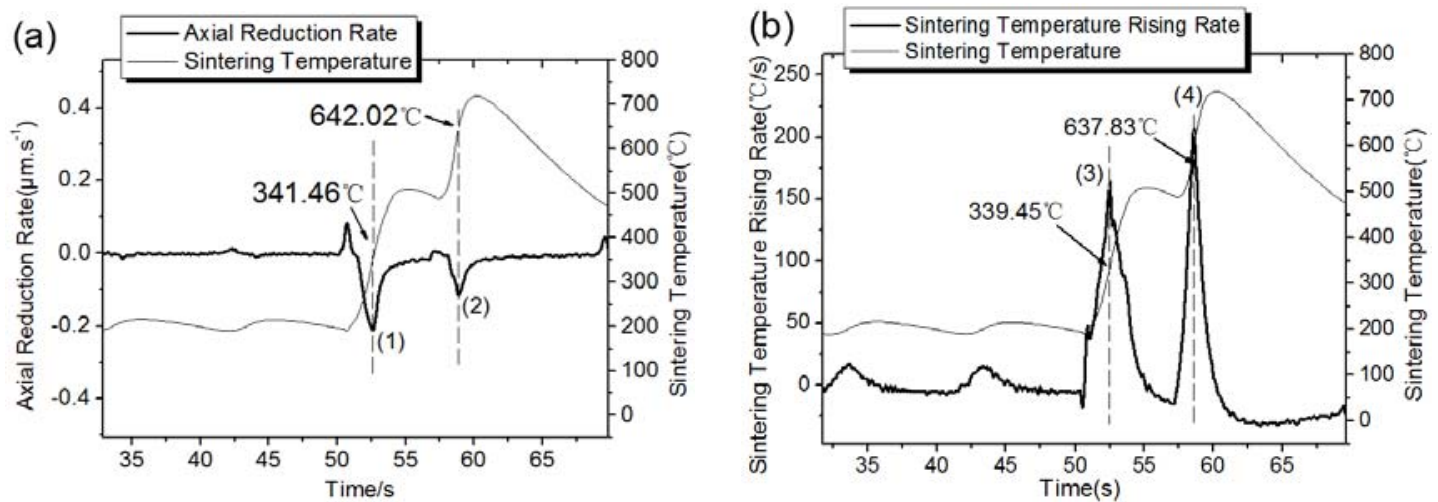

Fig.4 (a) the temperature- axial reduction rate and (b) temperature-temperature rising rate of the $7 \#$ micro-gear, as a function of time. 
Two functions of temperature-temperature rising rate and temperature-axial reduction rate during the temperature-rise process are presented in Fig.4. Fig4(a) shows the change of axial reduction rate during temperature-rise period. There are two noticeable increases found in the axial reduction rate around $341.46{ }^{\circ} \mathrm{C}$ (peak (1)) and $642.02{ }^{\circ} \mathrm{C}$ (peak (2)). At the same time, in Fig.4 (b), it can be seen that there are two peaks in the temperature rate: at $339.45^{\circ} \mathrm{C}$ (peak (3)) and $637.83^{\circ} \mathrm{C}$ (peak (4)), these results indicating that under the effect of coupled multi-physical fields, the sintering kinetics can be described as: (i) a first sintering step of the deformation of the copper particles occurring at approximately $340{ }^{\circ} \mathrm{C}$ before interfacial melting; (ii) second step associated with interfaces melting between particles at approximately $640{ }^{\circ} \mathrm{C}$.
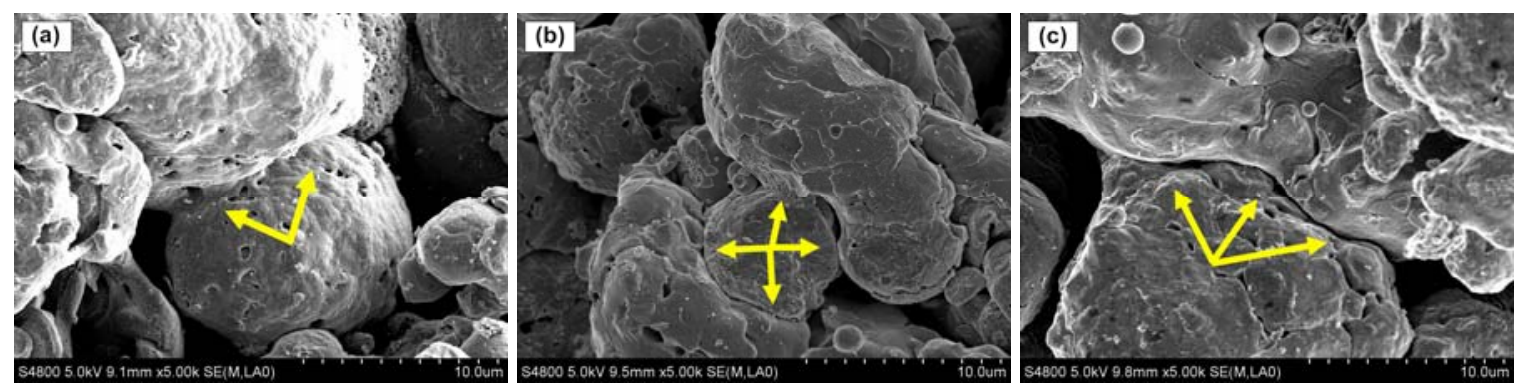

Fig.5 SEM micrograph of the shape and evolution of the particle's deformation behavior during sintering process: (a) $1 \#$, sintering at $200{ }^{\circ} \mathrm{C}$; (b) $2 \#$, sintering at $300{ }^{\circ} \mathrm{C}$; (c) $3 \#$, sintering at $400{ }^{\circ} \mathrm{C}$

Particles' plastic deformation. The shape and evolution of the particle's deformation behavior during sintering is presented in Fig.5. Within the temperature-rise region of from $200{ }^{\circ} \mathrm{C}$ to $400{ }^{\circ} \mathrm{C}$, the effect of the multi-physical fields is in reducing the number and volume of contact pores, which increases the contact areas of particles, thus leading to a significant reduction in the axial direction. It can be seen that with the increase of sintering temperature, the contact state between particles was developed from "point contact" to "lineal contact" and then "surface contact". Lu and et al [6] have reported that if the temperatures at the contact areas between particles are high, the yield stresses of the material at the contact areas and the viscosity of the compact will decrease. Therefore, the deformation rate of the material at a contact area will be greater when the temperature is high, i.e., as the sintering temperature is increased, the deformation rate of the powder compact will increase greatly. Similarly, the distances between particles will decrease under a high pressure, and the contact areas will become larger. The macro-sized pores within the powder compact will become filled with neighboring powder particles due to plastic flow.

The basic theory of particle deformation depends on the coupled multi-physical fields activated forming process: forming of the component is enabled by the simultaneous action of a pressure field, a temperature field and an electric field. The AC current passing through the mould creates an electrical field, and causes the granular boundaries to heat up due to resistance heating of particles themselves. During the sintering process, the press mould and blank themselves are directly heated. This occurs either through the supply of energy from the outside via the press mould and/or by AC current flow through the powder system itself. Under typical current activated sintering, the temperature, current and pressure are not independent and thus the thermal effect of the current (Joule heating) cannot unambiguously be separated from the intrinsic role of the current [12, 13]. Because of the effect of electro-plasticity [14-16] and "size effects" [17], it was found that an electric field of $\sim 1$ $\mathrm{kV} / \mathrm{cm}$ significantly reduced the plastic flow and fracture stresses of metals at room temperature. It was subsequently determined that the electric field also lowered the brittle-to-ductile transition temperature and reduced the flow stress and increased the elongation at elevated temperatures. Here, the electric field plays a decisive role in achieving a good deformation of particles at a lower temperature. 

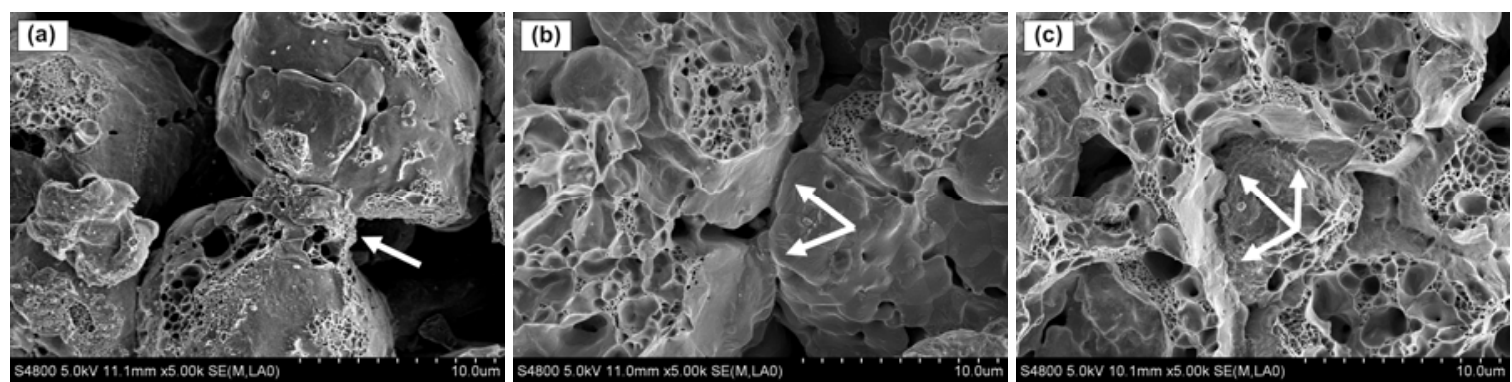

Fig.6 SEM micrographs of the shape and evolution of the copper particles' interfaces melting during sintering process: (a) $4 \#$, sintering at $500{ }^{\circ} \mathrm{C}$; (b) $5 \#$, sintering at $600{ }^{\circ} \mathrm{C}$; (c) $6 \#$, sintering at $700{ }^{\circ} \mathrm{C}$

Particles' interface melting. As shown in Fig.6, the particles' deformation to an equilibrium size and the melting of interfaces were almost complete for the copper micro-gear sintered at $600{ }^{\circ} \mathrm{C}$. The welded joints between particles observed in Fig. 6 are clear evidence of the formation of the liquid phase. The results confirmed interface melting as the second step of the sintering kinetics in the densification of the copper micro-gear prepared by Micro-FAST. Fig.6 (a) shows that provided that a significant amount of heat is generated at the interface of the particles, the melting point of fine powder particles is likely to be achieved at those interfaces that cause the generation of a liquid phase at local areas (see Fig.6 (c)). Once the liquid phase is formed, it will lead to the welding of the contact surface between particles [18] (see Fig.6 (b)). At the same time, with the aid of the pressure applied to the compact, the liquid phase flows into the vicinal pores due to the viscous flow and capillary force, which results in the disappearance of the interface between particles and fast densification of the compact [19].

Joule heating is the main heat source during the heating process and occurs without generating sparks, compared to SPS [20]. When an AC current passes through a compact, Joule heat will be generated at an interface due to the contact resistance. In the process of sintering, the change of Joule heat is affected by the interfacial contact resistance and current flow through the particles, namely, the contact surface among particles can gain a local high-temperature in the temperature-rise period. A certain amount of liquid phase is formed when the local temperature reaches the $\mathrm{Cu}$ liquidus temperature $\left(1083^{\circ} \mathrm{C}\right)$, which leads to the melting of the contact surface between particles [18, 21].

\section{Summary}

The sintering kinetics of Micro-FAST for the fabrication of copper micro-gears was investigated. From the work completed in this study the following conclusions may be drawn:

Copper micro-gears (module 0.2 and pitch diameter $1.6 \mathrm{~mm}$ ) can be fabricated by Micro-FAST. The density of the samples can reach over $99.01 \%$ when they were sintered at a relatively low sintering temperature $\left(700^{\circ} \mathrm{C}\right)$, a greater heating rate $\left(50^{\circ} \mathrm{C} / \mathrm{s}\right)$ and a pressure of $100 \mathrm{MPa}$.

The results suggest that the sintering process of copper micro-gears under coupled multi-physical field's activations can be described as a four-step process. However, according to the axial reduction curves, the temperature-rise period made a great contribution to the densification of the micro-gears.

It is deduced from the axial reduction-rate and temperature-rate curves that the deformation of the particles occurred at approximately $340{ }^{\circ} \mathrm{C}$ and that the interfaces melting of the particles occurred at approximately $640{ }^{\circ} \mathrm{C}$. This happens either through the supply of external energy via the press mould and/or by AC current flow through the powder/blank itself. Here, the electric field plays a decisive role in generating Joule heating of the particles their-selves and at the interface areas of the particles.

\section{Acknowledgements}

The authors would like to acknowledge the support from the National Nature Science Foundation of China (no.51275322) and the UK Royal Society / China NSFC International Exchanges Programme (no.51311130134) on the collaborative development of a new micro-manufacturing process. 


\section{References}

[1] Y. Qin, Micro-manufacturing engineering and technology, Elsevier, Oxford, 2010.

[2] W. Yun, D. Peilong, X. Zhenying, Y. Hua, W. Jiangping, W. Jingjing, A constitutive model for thin sheet metal in micro-forming considering first order size effects, Mater. Design 31 (2010) 1010-1014.

[3] A. Zavaliangos, J. Zhang, M. Krammer, J.R. Groza, Temperature evolution during field activated sintering, Mater. Sci. Eng. A 379 (2004) 218-228.

[4] Q. Hu, P. Luo, Y. Yan, J. Li, Microstructure evolution and wear properties of bulk MoSi2 fabricated by field activated sintering, Int. J. Refract. Met. H. 29 (2011) 470-477.

[5] K. Huang, Y. Yang, Y. Qin, G. Yang, Densification behavior of copper powder during the coupled multi-physics fields-activated microforming, Int. J Adv. Manuf. Tech. 69 (2013) 2651-2657.

[6] D. Lu, Y. Yang, Y. Qin, G. Yang, Forming Microgears by Micro-FAST Technology, J. Microelectromech. S., 22 (2013) 708-715.

[7] V.V. Dabhade, T.R.R. Mohan, P. Ramakrishnan, Initial sintering kinetics of attrition milled nanocrystalline titanium powders, Mater. Sci. Eng. A (2007) 386-394.

[8] F.F. Lange, Densification of powder compacts: An unfinished story, J. Eur. Ceram. Soc. 28 (2008) 1509-1516.

[9] H. Borodianska, D. Demirskyi, Y. Sakka, P. Badica, O. Vasylkiv, Grain boundary diffusion driven spark plasma sintering of nanocrystalline zirconia, Ceram. Int. 38 (2012) 4385-4389.

[10] J.S. Lee, L. Klinger, E. Rabkin, Particle rearrangement during sintering of heterogeneous powder mixtures: A combined experimental and theoretical study, Acta Mater. 60 (2012) 123-130.

[11] A. Du, Y. Yang, Y. Qin, G. Yang, Effects of Heating Rate and Sintering Temperature on 316 L Stainless Steel Powders Sintered Under Multiphysical Field Coupling, Mater. Manuf. Process 28 (2012) 66-71.

[12] Y.V.R.K. Prasad, K.P. Rao, Mechanisms of high temperature deformation in electrolytic copper in extended ranges of temperature and strain rate, Mater. Sci. Eng. A 374 (2004) 335-341.

[13] K. Feng, Y. Yang, M. Hong, J. Wu, S. Lan, Intensified sintering of iron powders under the action of an electric field: Effect of technologic parameter on sintering densification, J. Mater. Process Tech. 208 (2008) 264-269.

[14] Di Yang, H. Conrad, Influence of an electric field on the superplastic deformation of 3Y-TZP, Scripta Mater. 36 (1997) 1431-1435.

[15] A. Fais, Processing characteristics and parameters in capacitor discharge sintering, J Mater. Process Tech. 210 (2010) 2223-2230.

[16] H. Conrad, Electroplasticity in metals and ceramics, Mater. Sci. Eng. A 287 (2000) 276-287.

[17] J. Xu, B. Guo, C. Wang, D. Shan, Blanking clearance and grain size effects on micro deformation behavior and fracture in micro-blanking of brass foil, Int. J Mach. Tool. Manuf. (2012) 27-34.

[18]N. Beri, S. Maheshwari, C. Sharma, A. Kumar, Technological advancement in electrical discharge machining with powder metallurgy processed electrodes: a review, Mater. Manuf. Process 25 (2010) 1186-1197.

[19]A. Maximenko, E. Olevsky, Homogeneity of isostatic pressure-assisted sintering of agglomerated powder, Int. J Solids Struct. 42 (2005) 503-515.

[20]Y. Zhou, K. Hirao, Y. Yamauchi, S. Kanzaki, Effects of heating rate and particle size on pulse electric current sintering of alumina, Scripta Mater. 48 (2003) 1631-1636.

[21]L. Olmos, C.L. Martin, D. Bouvard, Sintering of mixtures of powders: Experiments and modelling, Powder Tech. 190 (2009) 134-140. 